\title{
Sequence-related amplified polymorphism (SRAP) markers, an efficient and affordable tool for evaluation genetic diversity in forest areas
}

\author{
Tzvetelina Zagorcheva ${ }^{1}$, Krasimir Rusanov ${ }^{1}$, Eirini Bosmali², \\ Panagiotis Madesis ${ }^{2}$, Ivan Tsvetkov ${ }^{1}$, Ivan Atanassov ${ }^{1}$
}

1 AgroBioInstitute, Agricultural Academy, 8 Dragan Tsankov Blvd., 1164, Sofia, Bulgaria

2 Institute of Applied Biosciences, Centre for Research and Technology Hellas, $6^{\text {th }} \mathrm{km}$ Charilaou-Thermi Road, 57001 Thessaloniki, Greece

Corresponding author: Ivan Atanassov (ivan_atanassov@abv.bg)

Academic editor: V. Gyuleva | Received 10 March 2020 | Accepted 12 April 2020 | Published 30 June 2020

Citation: Zagorcheva T., K. Rusanov, E. Bosmali, P. Madesis, I. Tsvetkov, I. Atanassov (2020) Sequence-related amplified polymorphism (SRAP) markers, an efficient and affordable tool for evaluation genetic diversity in forest areas. Silva Balcanica 21(1): 41-46. https://doi.org/10.3897/silvabalcanica.21.e54699

\begin{abstract}
This article describes testing the application of SRAP (sequence-related amplified polymorphism) markers for characterisation of a small set of plants of Quercus coccifera $\mathrm{L}$ and samples from 25 other forest tree species. The results suggest that SRAP markers could be used as an affordable and efficient tool for the characterisation of the genetic diversity in populations of tree species as a part of the characterisation of forest biodiversity and the related decision making and management.
\end{abstract}

\section{Keywords}

SRAP markers, genetic diversity, tree, forest areas

\section{Introduction}

Genetic diversity is well recognised as an essential and crucial part of biodiversity of forest area ecosystems (Ivetić, Devetaković, 2017). It provides the ground for longterm adaptive potential of the species, supporting their efficient adaptation to local and changing environmental conditions. The genetic diversity of forest species could be 
largely influenced by the applied silvicultural and forest management practices (Aravanopoulos, 2018; Zhelev, Aneva, 2019). Therefore, the sustainable management and utilisation of multipurpose forests, as well as decision making and the application of various forest management and conservation practices requires and adequate, on purpose and long-term evaluation of genetic diversity of target species populations (Hill et al., 2019). All this increases the demand for the development and routine application of efficient and affordable molecular markers and experimental procedures for the evaluation of the genetic diversity of forest species populations (Fussi et al., 2016).

During the last decade, SRAP (sequence-related amplified polymorphism) markers developed by $\mathrm{Li}$ and Quiros have been widely and successfully applied in various genetic studies involving model and crop plant species (Li, Quiros, 2001; Robarts, Wolfe, 2014). However, the application of this marker system in genetic studies on forest species populations is not well exploited. Here we report the application of SRAP markers for phylogenetic analysis of a small set of plants of Quercus coccifera $\mathrm{L}$ and genetic diversity analysis of samples from a set of 25 other forest species. The possible implications of SRAP markers for routine genetic diversity evaluation of forest species populations are discussed.

\section{Material and Methods}

\section{Plant material and DNA extraction}

Leaf samples from three to six individual plants of 25 forest plant species, described in Table 1, were collected from the State Forest Nursery, Elin Pelin, Bulgaria, and the National School of Forestry, Velingrad, Bulgaria. The samples from Quercus coccifera L were collected from the Natural Park of Pindus, Greece. All samples were transported to the laboratory in a cooling box, snap frozen in liquid nitrogen and stored at $-80^{\circ} \mathrm{C}$ until DNA isolation. Total genomic DNA was extracted using the CTAB method (Murray, Thompson, 1980), as chloroform / isoamyl alcohol (24:1) mixture was used within the extraction step instead of chloroform alone. Isolated DNA was quantified spectrophotometrically using Nanodrop 2000 (Thermo Scientific), diluted to $25 \mathrm{ng} \mu \mathrm{l}-1$ and stored at $-20^{\circ} \mathrm{C}$ until use.

\section{PCR amplification and fragment analysis}

The SRAP, 'ME' forward and 'EM' reverse primers, used in the study were designed according to Li \& Quiros (2001). The forward 'ME' primers were 5' end labelled with fluorescein amidite (FAM) dye. The PCR reactions were carried out in a final volume of $25 \mu \mathrm{l}$, containing: $2 \mu \mathrm{l}$ of DNA template $\left(25 \mathrm{ng}^{-1}\right), 0.1 \mu \mathrm{M}$ of the forward and reverse primers and $12.5 \mu \mathrm{l}$ of DreamTaq DNA Polymerase (Thermo Fisher Scientific). Samples were amplified using the following program: $5 \mathrm{~min}$ at $94^{\circ} \mathrm{C}$; 
$3 \mathrm{x}$ cycles of $1 \mathrm{~min}$ at $94^{\circ} \mathrm{C}, 1 \mathrm{~min}$ at $35^{\circ} \mathrm{C}$ and $1 \mathrm{~min}$ at $72^{\circ} \mathrm{C} ; 35 \mathrm{x}$ cycles of $1 \mathrm{~min}$ at $94^{\circ} \mathrm{C}, 1 \mathrm{~min}$ at $50^{\circ} \mathrm{C}$ and $1 \mathrm{~min}$ at $72^{\circ} \mathrm{C}$; and a final elongation step of $3 \mathrm{~min}$ at $72^{\circ} \mathrm{C}$. The PCR products were diluted tenfold. For electrophoresis, $1 \mu \mathrm{l}$ of the diluted PCR amplified product was mixed with $0.5 \mu \mathrm{l}$ of the GeneScan 500 LIZ Size Standard and $9 \mu \mathrm{l}$ of Hi-Di Formamide (Thermo Fisher Scientific Inc). The mixture was denatured and analysed on Applied Biosystems 3130 Genetic Analyzer using 3130 POP-7 Polymer and $36 \mathrm{~cm}$ capillary array (Thermo Fisher Scientific).

\section{Data analysis}

SRAP fragment analysis was performed with the GeneMapper Analysis Software v4.0 (Thermo Fisher Scientific). The threshold for peaks assignation was set to 350 relative fluorescence units after preliminary testing between 200 and 400 at a step of 50. Fragment analysis was carried out for fragment sizes in the range of 50-950 bp. All clearly distinguished SRAP fragments were scored as (1) for presence and ( 0 ) for absence and the obtained data were used for the construction of a SRAP data matrix. The phylogenetic analysis and analysis of molecular variance (AMOVA) were performed with the FAMD software (Schlueter, Harris, 2006). Structure 2.3.4 was used for analysis of the genetic structure (Pritchard et al., 2000). The most probable number of clusters (K) was obtained using the Evanno et al. method (Evanno et al., 2005). Analysis of variance (ANOVA) was performed using IBM SPSS Statistics v25.

\section{Results and Discussion}

Three primer pairs, namely: EM3 x ME4; EM1 x ME8; EM7 x ME1, were selected after a preliminary SRAP analysis of samples from three different species by using 100 SRAP primer pairs, resembling all possible ME x EM combinations (Li, Quiros, 2001). The selected primer pairs generated SRAP pattern and electropherograms with relatively low noise and distinct and well- observed SRAP peaks. The selected SRAP primer pairs were further used for the SRAP analysis of all samples.

The obtained results, shown in Table 1, demonstrated the successful SRAP fragment amplification from DNA samples of all tested plant species. The results further demonstrated large variations of the observed total number of SRAP fragments, amplified from samples within the same species, as well between the samples from different species. The data showed that the EM3 x ME4 pair resulted in an amplification of a higher number of SRAP fragments than the other two tested primer pairs (Table 1). Similarly, the results showed large variation of the portion of polymorphic SRAP fragments observed in the set of samples from each tested species, ranging from $9.5 \%$ to $87.5 \%$ polymorphic fragments. ANOVA analysis showed no significant difference between the average percentages of polymorphic SRAP fragments generated by the three tested primer pairs (Table 1). The selected primer pairs were further applied for the characterisation of a small set of 19 samples of Quercus coc- 
Table I. Summary of SRAP fragments data following SRAP analysis of plants of Quercus coccifera L: $(\min ) /(\max )$ - the minimal / maximal total number of SRAP fragments observed from the samples from the tested species \& primer pair in all analysed genotypes; $(\mathrm{PPF})$ - percent of the polymorphic fragments for the tested primer pair / species.

\begin{tabular}{|c|c|c|c|c|c|c|c|c|c|}
\hline \multirow{2}{*}{$\begin{array}{l}\text { Origin of the samples: } \\
\text { (Family) Species }\end{array}$} & \multicolumn{3}{|c|}{ EM3 x ME4* } & \multicolumn{3}{|c|}{ EM1 x ME8* } & \multicolumn{3}{|c|}{ EM7 x ME1* } \\
\hline & $\min$ & $\max$ & PPF & $\min$ & $\max$ & PPF & $\min$ & $\max$ & PPF \\
\hline (B) Betula pendula Roth & 21 & 35 & $42.1 \%$ & 14 & 21 & $52.5 \%$ & 6 & 10 & $30.4 \%$ \\
\hline (C) Cupressus arizonica Greene & 17 & 22 & $37.0 \%$ & 8 & 13 & $37.9 \%$ & 10 & 18 & $36.7 \%$ \\
\hline (C) Juniperus communis L. & 10 & 12 & $16.2 \%$ & 7 & 11 & $10.9 \%$ & 11 & 12 & $26.1 \%$ \\
\hline (C) Juniperus oxycedrus L & 5 & 14 & $52.5 \%$ & 6 & 28 & $28.9 \%$ & 6 & 8 & $23.8 \%$ \\
\hline (C) Platycladus orientalis (L.) Franco & 16 & 24 & $28.1 \%$ & 11 & 18 & $41.2 \%$ & 9 & 15 & $29.4 \%$ \\
\hline (C) Thuja occidentalis L. & 10 & 11 & $24.6 \%$ & 5 & 6 & $25.4 \%$ & 16 & 17 & $50.0 \%$ \\
\hline $\begin{array}{l}\text { (C) Sequoiadendron giganteum (Lindl.) } \\
\text { J.Buchholz }\end{array}$ & 25 & 28 & $39.3 \%$ & 10 & 20 & $87.5 \%$ & 4 & 22 & $30.6 \%$ \\
\hline $\begin{array}{l}\text { (C) Chamaecyparis lawsoniana } \\
\text { (A.Murray bis) Parl }\end{array}$ & 15 & 22 & $28.1 \%$ & 3 & 8 & $36.4 \%$ & 5 & 9 & $28.6 \%$ \\
\hline (F) Quercus petraea (Matt.) Liebl. & 13 & 15 & $28.6 \%$ & 5 & 10 & $27.1 \%$ & 14 & 17 & $25.7 \%$ \\
\hline (F) Quercus robur $\mathrm{L}$. & 10 & 14 & $40.0 \%$ & 15 & 17 & $36.8 \%$ & 11 & 15 & $39.4 \%$ \\
\hline (F) Quercus rubra L. & 32 & 34 & $28.6 \%$ & 14 & 17 & $28.6 \%$ & 12 & 21 & $45.3 \%$ \\
\hline (F) Quercus coccifera $\mathrm{L}$. & 8 & 31 & $42.0 \%$ & 6 & 20 & $51.3 \%$ & 8 & 22 & $54.0 \%$ \\
\hline (M) Tilia cordata Mill. & 11 & 22 & $29.7 \%$ & 11 & 16 & $32.2 \%$ & 20 & 21 & $22.2 \%$ \\
\hline (M) Tilia tomentosa Moench & 15 & 16 & $54.5 \%$ & 4 & 6 & $20.8 \%$ & 3 & 12 & $40.0 \%$ \\
\hline (P) Pinus sylvestris L. & 21 & 38 & $52.2 \%$ & 7 & 17 & $44.2 \%$ & 7 & 21 & $36.9 \%$ \\
\hline (P) Pinus nigra J.F.Arnold) & 3 & 27 & $40.0 \%$ & 5 & 13 & $41.8 \%$ & 5 & 20 & $40.0 \%$ \\
\hline (P) Pseudotsuga menziesii (Mirb.) Franco) & 18 & 21 & $50.5 \%$ & 7 & 18 & $64.2 \%$ & 6 & 17 & $42.2 \%$ \\
\hline (P) Picea abies (L.) H.Karst & 21 & 54 & $77.5 \%$ & 7 & 11 & $44.3 \%$ & 13 & 23 & $33.3 \%$ \\
\hline (P) Picea pungens Engelm. & 22 & 46 & $44.0 \%$ & 2 & 5 & $20.7 \%$ & 5 & 14 & $17.0 \%$ \\
\hline (P) Abies alba Mill. & 14 & 35 & $39.2 \%$ & 4 & 15 & $77.5 \%$ & 7 & 15 & $32.7 \%$ \\
\hline (P) Abies chephalonica Loudon & 30 & 45 & $25.9 \%$ & 6 & 12 & $11.8 \%$ & 11 & 14 & $28.6 \%$ \\
\hline (P) Abies concolor (Gordon) Lindl. ex Hildebr. & 22 & 38 & $35.9 \%$ & 7 & 8 & $23.5 \%$ & 11 & 13 & $34.5 \%$ \\
\hline $\begin{array}{l}\text { (P) Cedrus atlantica (Endl.) } \\
\text { Manetti ex Carrière }\end{array}$ & 16 & 30 & $31.0 \%$ & 6 & 8 & $73.0 \%$ & 10 & 12 & $33.3 \%$ \\
\hline (P) Cedrus deodara (Roxb. ex D.Don) G.Don & 15 & 34 & $42.9 \%$ & 6 & 12 & $30.8 \%$ & 11 & 12 & $9.5 \%$ \\
\hline (S) Acer pseudoplatanus L. & 20 & 24 & $41.7 \%$ & 5 & 18 & $17.6 \%$ & 27 & 28 & $24.3 \%$ \\
\hline $\begin{array}{l}\text { Average percentage of polymorphic SRAP } \\
\text { fragments: }\end{array}$ & \multicolumn{3}{|c|}{$38.9 \%+/-12.7 \%$} & \multicolumn{3}{|c|}{$38.7 \%+/-20.0 \%$} & \multicolumn{3}{|c|}{$32.6 \%+/-10.0 \%$} \\
\hline
\end{tabular}

cifera L. collected from the Natural Park of Pindus, Greece. The obtained SRAP data were used for the construction of a phylogenetic tree (Fig. 1). The results showed that the obtained SRAP data allow to resolve all tested plants as the calculated PIC (polymorphic information content) ranged between 0.16 for EM7 x ME1 and 0.19 for the EM3 x ME 4 primer pair. Our data suggested no existence of distinct populations of $Q$. coccifera $L$. among the analysed set of samples, as evidenced by the results obtained from the Structure software. The observed number of the detected SRAP fragments and the portion of the polymorphic fragments are within the range 


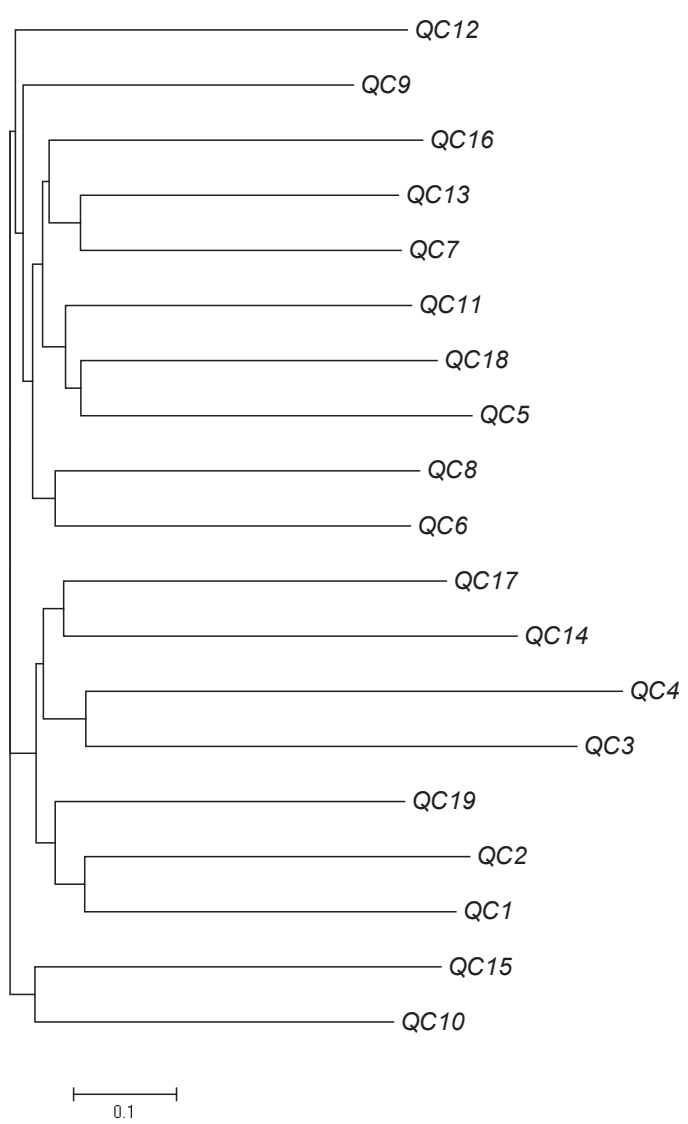

Figure I. Neighbor joining phylogenetic tree constructed from SRAP data from 19 samples of Q. coccifera collected from the National Park of Pindus, Greece.

of other reported SRAP studies on forest tree species including: Pinus koraiensis (Feng et al., 2009), Quercus acutissima (Ye, Zeng, 2009) and Acer sp. (Li et al., 2010). During the past two decades, the molecular marker studies on genetic diversity of tree populations from forest areas employed predominantly SSR (Aravanopoulos, 2018; Ivetić, Devetaković, 2017; Robarts, Wolfe, 2014). This requires preliminary development of efficient SSR markers, including PCR primer pairs and amplification conditions, for the target tree species. Additionally, a single SSR marker usually targets a single locus in the plant genome and the application of a set of SSR markers is necessary to cover larger number of loci for population studies. This largely limits the molecular marker applications to restricted number of genetic diversity studies of forest tree populations. Taking together the described here results suggest that SRAP analysis, employing a small number of primer pairs, could be readily used as an affordable and efficient tool for testing the genetic diversity of populations from tree species, as a part of the overall biodiversity evaluation in forest areas. 


\section{Acknowledgments}

This work was supported through the INTERREG Balkan-Mediterranean Project BIOPROSPECT "Conservation and sustainable capitalization of biodiversity in forested areas" (BMP1/2.1/2336/2017).

\section{References}

Aravanopoulos, F.A. 2018. Do silviculture and forest management affect the genetic diversity and structure of long-impacted forest tree populations? - Forests, 9(6), 355.

Evanno, G., S. Regnaut, J. Goudet. 2005. Detecting the number of clusters of individuals using the software STRUCTURE: a simulation study. - Molecular ecology, 14(8), 2611-2620.

Feng, F., M. Chen, D. Zhang, X. Sui, S. Han. 2009. Application of SRAP in the genetic diversity of Pinus koraiensis of different provenances. African Journal of Biotechnology, 8(6), 1000-1008.

Fussi, B., M. Westergren, F. Aravanopoulos, R. Baier, D. Kavaliauskas, D. Finzgar, P. Alizoti, G. Bozic, E. Avramidou, M. Konnert. 2016. Forest genetic monitoring: an overview of concepts and definitions. - Environmental Monitoring and Assessment, 188(8), 493.

Hill, S.L., A. Arnell, S.H. Butchart, C. Hilton-Taylor, C. Ciciarelli, C. Davis, E. Dinerstein, A. Purvis, N.D. Burgess. 2019. Measuring forest biodiversity status and changes globally. Frontiers in Forests and Global Change, 2, 70.

Ivetić, V., J. Devetaković. 2017. Concerns and evidence on genetic diversity in planted forests. - Reforesta 3, 196-207.

Li, G., C.F. Quiros. 2001. Sequence-related amplified polymorphism (SRAP), a new marker system based on a simple PCR reaction: its application to mapping and gene tagging in Brassica. - Theoretical and applied genetics, 103(2-3), 455-461.

Li, Q., X. Liu, J. Su, J. Tao. 2010. Genetic diversity of Acer L. germplasm revealed by sequence-related amplified polymorphism (SRAP) markers. - Jiangsu Journal of Agricultural Sciences, 26(5), 1032-1036.

Murray, M., W.F. Thompson. 1980. Rapid isolation of high molecular weight plant DNA. Nucleic acids research, 8(19), 4321-4326.

Pritchard, J.K., M. Stephens, P. Donnelly. 2000. Inference of population structure using multilocus genotype data. - Genetics, 155(2), 945-959.

Robarts, D.W., A. D. Wolfe. 2014. Sequence-related amplified polymorphism (SRAP) markers: A potential resource for studies in plant molecular biology. - Applications in plant sciences, 2(7), apps.1400017.

Schlueter, P.M., S.A. Harris. 2006. Analysis of multilocus fingerprinting data sets containing missing data. - Molecular Ecology Notes, 6(2), 569-572.

Ye, Q., X. Zeng. 2009. Optimization of SRAP-PCR system and genetic diversity analysis in Quercus acutissima Carr. - Biotechnology, 19, 25-27.

Zhelev, P., I.Y. Aneva. 2019. Climate Change, Biodiversity and Forest Genetic Resources: A Bulgarian Perspective. - In: Šijačić-Nikolić M., Milovanović J., Nonić M. (Eds.) Forests of Southeast Europe Under a Changing Climate. Advances in Global Change Research, 65. Springer, Cham, pp. 409-427 